\title{
Dietary supplements containing prohibited substances: A review (Part 1)
}

\author{
P van der Bijl, BSc Hons (Chem), BSc Hons (Pharmacol), BChD, PhD, DSc \\ Emeritus Professor and Former Head, Department of Pharmacology, Faculty of Medicine and Health Sciences, Stellenbosch University, Tygerberg, Cape Town, \\ South Africa; and Invited Foreign Professor, Department of Pharmacology, Pirigov's Russian National Research Medical University, Moscow, Russia
}

Corresponding author: P van der Bijl (pietervanderbijlcpt@gmail.com)

\begin{abstract}
Dietary supplements and chemical agents have been used for a number of decades among athletes striving to achieve increased strength and performance. This has led to a huge, growing market for the food supplement industry. The latter's products are classified as 'foods' rather than drugs and are therefore free of the stringent requirements for registration of pharmaceuticals, i.e. no safety and efficacy data are required prior to registration. During the past decade, some dietary supplements have been shown to contain pharmaceutically active components not adequately identified on their package labels. These pharmaceuticals may have unintentionally entered the product or may have been intentionally added. Although the concentrations of these substances may be low and devoid of health or performance-enhancing effects, they may lead to positive doping tests. In Part 1 of this two-part review, a selection of the World Anti-Doping Agency-prohibited illegal stimulants, i.e. ephedrine, pseudoephedrine, sibutramine and methylhexaneamine, are discussed. Certain food supplement labels do mention the presence of natural sources of illegal stimulants, e.g. Ephedra sinica (ephedrine), but do not refer to the chemical entities of ephedrine and its analogues as such. The pharmacological adverse effects of stimulants, in particular those on the cardiovascular system, are briefly reviewed. Suggestions for avoiding these pitfalls are made.
\end{abstract}

S Afr J SM 2014;26(2):59-61. DOI:10.7196/SAJSM.552

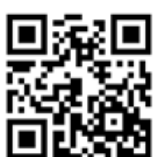

While it is well recognised that a balanced diet is the foundation for developing optimal training and performance, competitive sport and strenuous physical activity make demands on the human body beyond its normal physiological range. ${ }^{[1]}$ Some athletes may therefore benefit from additional supplements to help maintain homeostasis with adequate nutrients and energy in specific circumstances, especially where food intake or choice is restricted. For this reason, dietary supplements have been used by athletes for many years to boost, even by small margins, their strength and performance. ${ }^{[2-4]}$ Pressure to perform and the potential rewards coupled with success are powerful driving forces for many top athletes to continue striving for that chemical competitive edge. For this purpose, they use these dietary supplements as part of their regular training or competition routine, even if the rationale for using these products is not always underpinned by solid evidence-based research. ${ }^{[1]}$ Supplements commonly used include vitamins, minerals, protein, creatine and various ergogenic compounds. While some supplements indeed enhance athletic performance, many have no proven benefits, are of uncertain content and purity, and may have serious systemic adverse effects, including death.

The practice of using dietary supplements among the population at large and athletes at all levels of competition has led to a huge, continuously growing, multibillion dollar industry with a worldwide market estimated at more than $\$ 142$ billion in 2011 and expected to rise to $\$ 205$ billion by $2017 \cdot{ }^{[5]}$ Coupled with aggressive marketing techniques in which bold as well as unsubstantiated claims are frequently made, this explosive growth has been further fuelled in many countries worldwide which have acts similar to the Dietary Supplement Health and Education Act (DSHEA), which was passed by the US Congress in 1994. In essence, these acts allow substances that are marketed as dietary supplements to be regulated as foods rather than as pharmaceuticals. A dietary supplement is a product taken orally that contains a 'dietary ingredient' intended to supplement the diet. The 'dietary ingredients' in these products may include vitamins, minerals, herbs or other botanicals, amino acids, and substances such as enzymes, organ tissues, glandulars and metabolites. ${ }^{[6]}$ Dietary supplements can be extracts or concentrates, and may be found in many forms such as tablets, capsules, softgels, gelcaps, liquids or powders. They can also be in other forms, such as a bar, but if they are, information on the label must not represent the product as a conventional food or a sole item of a meal or diet. ${ }^{[6]}$ Whatever their form may be, the DSHEA places dietary supplements in a special category under the general umbrella of 'foods', not drugs, and requires that every supplement be labelled a dietary supplement. ${ }^{[6]}$ Other than for pharmaceuticals, in which regulatory authorities scrutinise data on safety and efficacy before giving marketing approval, supplement manufacturers do not have to prove efficacy for their products, providing that they do not claim that their preparations can be used to diagnose, cure, mitigate, treat or prevent diseases. Furthermore, manufacturers of dietary supplements do not have to demonstrate their safety, and the burden rests on regulatory authorities to show that a particular product is harmful before steps can be taken to ensure its removal from the market. 
These dietary supplement regulations have facilitated their availability not only to the population at large and noncompeting amateurs, but especially to professional athletes in whom their use, often in megadoses, is widespread. ${ }^{[7,8]}$ Estimated use in the latter group varies between $44 \%$ and $100 \%$; however, this very much depends not only on the type of sport but also on the level of competition and age and gender of the athletes. ${ }^{[8-11]}$ Large quantities of nutrients, commonly found in normal human diets, are consumed without there being much knowledge of possible health risks and the maximum daily safe doses involved. Over the past decade, a new hazard related to dietary supplement use has been identified in that some products, marketed under the aegis of the regulatory requirements for foods, have been shown to contain unapproved pharmaceutically active ingredients. These dietary regulations have allowed manufacturers to bypass the necessity of providing safety and efficacy data for their products. It is of great concern that a wide variety of dietary supplements contain ingredients not adequately chemically identified on their packaging labels. These ingredients, which are sometimes listed as 'natural,' 'herbal' or otherwise, may constitute prohibited substances. They may have inadvertently entered the product, possibly as a result of accidental cross-contamination in manufacturing plants, or may have been intentionally added to the supplement, posing a potential health hazard to all consumers. ${ }^{[4,12]}$ While concentrations of these non-approved substances may be too small to achieve any health or performance-enhancing effects, they may be large enough for athletes to fail a doping test, and scandals appear to be more frequent. ${ }^{[4]}$ In recent years, there has been an increase in the number of dietary supplements containing unapproved pharmaceutical ingredients, recalled by the Food and Drug Administration. ${ }^{[13]}$ With as many as 150 million citizens in the USA consuming dietary supplements in some form or another, the challenges that are posed by this growing and unregulated industry are enormous.

\section{Ephedrine and pseudoephedrine}

Although stimulants can easily be detected in laboratories, they are still popular among athletes. Because the list of legal and illegal stimulants is extensive, only a selection will be discussed here.

Studies have shown that certain dietary supplements have contained prohibited substances such as ephedrine and its analogues (pseudoephedrine, methylephedrine, etc.), caffeine, 3,4-methylenedioxy-N-methylamphetamine (MDMA, or 'ecstasy') and other amphetamine-related compounds, which may or may not be declared on packaging labels. ${ }^{[12]}$ Ephedrine and its congeners are used as nasal decongestants and as pressor agents for hypotension. While caffeine is no longer considered a prohibited substance by the World Anti-doping Agency (WADA) since 2004, the use of ephedrine and its analogues and MDMA is banned during competition by this organisation. ${ }^{[14]}$ On certain food supplement labels, natural sources of ephedrine, e.g. Ephedra sinica - a species of ephedra (ma huang), which contains the alkaloids ephedrine and pseudoephedrine - are mentioned instead of the chemical entities of ephedrine and its analogues. Similarly, synephrine is obtained from Citrus aurantium. Both plant products have been found in dietary supplements that were labelled as 'ephedrine free'. Apart from the doping infringement aspects of supplements containing prohibited stimulants, there are potential health risks involved that should not be ignored. Ephedrine has structural similarities with amphetamine and therefore has similar modes of action and a comparable side-effect profile. Both ephedrine and pseudoephedrine are stimulants, but they affect physical achievement differently. Ephedrine adversely affects running time over $10 \mathrm{~km}$, but anaerobic performance of athletes increases. ${ }^{[15,16]}$ Supporting evidence found in a meta-analysis of eight studies was, however, insufficient to demonstrate clear benefits in performance with ephedrine. ${ }^{[17]}$ Similarly, improvements in fatigue and cycling performance with pseudoephedrine ingestion could not be found, but in a limited study an improvement in running times over $1.5 \mathrm{~km}$ following the use of this pharmaceutical agent was shown. ${ }^{[18-20]}$

Adverse effects of ephedrine may be serious. A two- to threefold risk of anxiety, increased irritability and agitation (psychiatric symptoms), insomnia, tremors (autonomic system symptoms) and heart palpitations (cardiac symptoms) were found on analysis of 71 case reports and 50 clinical trials. ${ }^{[17]}$ In the foregoing analysis of cases of death, myocardial infarctions, cerebrovascular accidents, seizures and psychoses were found in some reports. Regarding pseudoephedrine anxiety, gastrointestinal disturbances and tremors have been reported. ${ }^{[21]}$ Both ephedrine and pseudoephedrine have been declared prohibited substances by the WADA. ${ }^{[14]}$

\section{Sibutramine}

Dietary supplements adulterated with sibutramine, an anti-obesity agent, which do not mention the presence of this compound on the packaging label, have also appeared on the market. Sibutramine has been found in products advertised as 'pure herbal' slimming capsules and 'natural' tea. ${ }^{[22-24]}$ Urinary metabolites of sibutramine were found in detectable quantities 50 hours after administration of a single 'dose' of tea to a volunteer. ${ }^{[24]}$ This synthetic anorectic drug, which only has market approval as a prescription anti-obesity agent, has been on the WADA prohibited list since 2006. Furthermore, market withdrawal of sibutramine was recommended by the European Medicines Agency at the beginning of 2010. This agent produces severe systemic adverse effects, blood pressure elevation and cardiac effects (tachycardia), and patients using sibutramine are required to be monitored by a physician experienced in the treatment of obesity and familiar with this agent, on a regular basis.

\section{Methylhexaneamine}

Methylhexaneamine, a stimulant originally intended to be marketed as a nasal decongestant, has been detected as an ingredient of dietary supplements and was declared a prohibited compound by the WADA in $2009 .{ }^{[25]}$ The serious adverse effects of this stimulant have recently been highlighted by a case report on the death of two US soldiers who were taking commercially available dietary supplements that contained methylhexaneamine. Both soldiers collapsed from cardiac arrest during physical exertion and ultimately died. ${ }^{[26]}$ The issues surrounding this stimulant have been complicated by the fact that methylhexaneamine is found on package labels under a very wide variety of chemical and non-chemical names, e.g. 1,3-dimethylamylamine, 1,3-dimethylpentylamine, 2-amino-4-methylhexane, 2-hexanamine, 4-methyl-2-hexanamine, 4-methyl-2-hexylamine, 4-methylhexan-2-amine, dimethylamylamine, methylhexaneamine, dimethylpentylamine, floradrene, forthan, forthane, fouramin, geranamine, geranium extract, geranium flower 
extract, geranium oil, geranium stems and leaves, metexaminum, methexaminum, etc. Only the names methylhexaneamine and dimethylpentylamine appear on the WADA 2011 list of prohibited agents, creating even further confusion among consumers and complicating identification. While geranium root extract or geranium oil are mentioned as natural sources of methylhexaneamine, the presence of this compound in these plant products could not be demonstrated on analysis, strengthening the suspicion that it was added during or after the manufacturing process. ${ }^{[27]}$

\section{Conclusion}

While food supplements and pharmaceutical agents may enhance strength and performance of athletes, there is insufficient scientific data to support this theory. Although stimulants have been widely used among athletes for performance enhancement, these substances are prohibited by the WADA. In addition, ingestion of stimulants via accidentally or intentionally contaminated dietary supplements may lead to failed doping tests and its consequences. The presence of stimulants in nutritional supplements may also lead to serious systemic adverse effects; athletes, coaches and sports doctors should be aware of these pitfalls when using or advising on the intake of these products. The risk of accidental ingestion of forbidden substances from dietary supplements can be diminished by using 'safe' products listed on databases such as those available in the Netherlands and Germany. ${ }^{[12]}$

\section{References}

1. Zadik Z, Nemet D, Eliakim A. Hormonal and metabolic effects of nutrition in athletes. J Pediatr Endocrinol Metab 2009;22(9):769-777. [http://dx.doi.org/10.1515/ JPEM.2009.22.9.769]

2. Jenkinson DM, Harbert AJ. Supplements and sports. Am Fam Physician 2008;78(9):1039-1046.

3. Bishop D. Dietary supplements and team-sport performance. Sports Medicine 2010;40(12):995-1017. [http://dx.doi.org/10.2165/11536870-000000000-00000]

4. Geyer H, Braun H, Burke LM, Stear SJ, Castell LM. A-Z of dietary supplements: Dietary supplements, sports nutrition foods and ergogenic aids for health and performance Part 22. Br J Sports Med 2011;45(9):752-754. [http://dx.doi.org/10.1136/ bjsports-2011-090180]

5. Transparency Market Research. Nutraceuticals Product Market is Expected to Reach USD 204.8 Billion Globally in 2017. www.transparencymarketresearch.com/globalnutraceuticals-product-market.html (accessed on 15 July 2013).

6. Food and Drug Administration. What is a Dietary Supplement? www.fda.gov/Food/ DietarySupplements/QADietarySupplements/default.htm [accessed on 15 May 2014].
7. Sundgot-Borgen J, Berglund B, Torstveit KM. Dietary supplements in Norwegian elite athletes - impact of international ranking and advisors. Scand J Med Sci Sports 2003;13(2):138-144. [http://dx.doi.org/10.1034/j.1600-0838.2003.10288.x]

8. Sobal J, Marquart LF. Vitamin/mineral supplement use among athletes: A review of the literature. Int J Sport Nutr 1994;4(4):320.

9. Erdman KA, Fung TS, Reimer RA. Influence of performance level on dietary supplementation in elite Canadian athletes. Med Sci Sports Exerc 2006;38(2):349356. [http://dx.doi.org/10.1249/01.mss.0000187332.92169.e0]

10. Maughan RJ, Depiesse F, Geyer H. The use of dietary supplements by athletes. J Sports Sci 2007;25(Suppl 1):S103-113. [http://dx.doi.org/10.1080/02640410701607395]

11. Striegel H, Simon P, Wurster C, Niess AM, Ulrich R. The use of dietary supplements among master athletes. Int J Sports Med 2006;27(3):236-241. [http://dx.doi. org/10.1055/s-2005-865648]

12. Geyer H, Parr MK, Koehler K, Mareck U, Schänzer W, Thevis M. Nutritional supplements cross-contaminated and faked with doping substances. J Mass Spectrom 2008;43(7):892-902. [http://dx.doi.org/10.1002/jms.1452]

13. Harel Z, Harel S, Wald R, Mamdani M, Bell CM. The frequency and characteristics of dietary supplement recalls in the United States. JAMA Intern Med 2013;173(10):926928. [http://dx.doi.org/10.1001/jamainternmed.2013.379]

14. World Anti Doping Agency. The 2013 Prohibited List. http://www.wada-ama.org/en/ world-anti-doping-program/sports-and-anti-doping-organizations/internationalstandards/prohibited-list/ (accessed on 15 May 2014).

15. Bell DG, McLellan TM, Sabiston CM. Effect of ingesting caffeine and ephedrine on 10 $\mathrm{km}$ run performance. Med Sci Sports Exerc 2002;34(2):344-349.

16. Bell DG, Jacobs I, Ellerington K. Effect of caffeine and ephedrine ingestion on anaerobic exercise performance. Med Sci Sports Exerc 2001;33(8):1399-1403. [http:// dx.doi.org/10.1097/00005768-200108000-00024]

17. Shekelle PG, Hardy ML, Morton SC, et al. Efficacy and safety of ephedra and ephedrine for weight loss and athletic performance: A meta-analysis. JAMA 2003;289(12):15371545. [http://dx.doi.org/10.1001/jama.289.12.1537]

18. Chu KS, Doherty TJ, Parise G, Milheiro JS, Tarnopolsky MA. A moderate dose of pseudoephedrine does not alter muscle contraction strength or anaerobic power. Clin J Sport Med 2002;12(6):387-390.

19. Gillies H, Derman WE, Noakes TD, Smith P, Evans A, Gabriels G. Pseudoephedrine is without ergogenic effects during prolonged exercise. J Appl Physio 1996;81(6):2611-2617.

20. Hodges K, Hancock S, Currell K, Hamilton B, Jeukendrup AE. Pseudoephedrine enhances performance in 1500 m runners. Med Sci Sports Exerc 2006;38(2):329333. [http://dx.doi.org/10.1249/01.mss.0000183201.79330.9c]

21. National Institutes of Health. Pseudoephedrine: What side effects can this medication cause? www.nlm.nih.gov/medlineplus/druginfo/meds/a682619.html (accessed on 15 May 2014).

22. Jung J, Hermanns-Clausen M, Weinmann W. Anorectic sibutramine detected in a Chinese herbal drug for weight loss. Forensic Sci Int 2006;161(2-3):221-222. [htt[:// dx.doi.org/10.1016/j.forsciint.2006.02.052]

23. Vidal C, Quandte S. Identification of a sibutramine-metabolite in patient urine after intake of a "pure herbal" Chinese slimming product. Ther Drug Monit 2006;28(5):690692. [http://dx.doi.org/10.1097/01.ftd.0000245392.33305.b0]

24. Koehler K, Geyer H, Guddat S, et al. Sibutramine found in chinese herbal slimming tea and capsules. In: Schänzer W, Geyer H, Gotzmann A, Mareck U, eds. Recent Advances in Doping Analysis. Cologne: Sportverlag Strauß, 2007:367.

25. Thevis M, Sigmund G, Geyer H, Schänzer W. Stimulants and doping in sport. Endocrino Metab Clin North Am 2010;39(1):89-105,ix. [http://dx. doi.org/10.1016/j.ecl.2009.10.011]

26. Eliason MJ, Eichner A, Cancio A, Bestervelt L, Adams BD, Deuster PA. Case reports: Death of active duty soldiers following ingestion of dietary supplements containing 1,3-dimethylamylamine (DMAA). Mil Med 2012;177(12):1455-1459.

27. Lisi A, Hasick N, Kazlauskas R, et al. Studies of new stimulants. Lecture held at the 29th Cologne Workshop on Dope Analysis, 15 February 2011, Cologne, Germany. 